\title{
Study on stress of change tooth profile parameters of new type double helical synchronous belt based on ANSYS Workbench
}

\author{
Jianhua Guo ${ }^{1, \text { a }}$, Xin $\mathrm{Yu}^{1, \mathrm{~b}}$, Qingxin Meng ${ }^{1, \mathrm{c}}$, Qingming $\mathrm{Hu}^{1, \mathrm{~d}}$ \\ ${ }^{1}$ Qiqihar University College of Electrical Engineering, 161006, Qiqihar \\ a guo1034@ sina.com, ${ }^{\mathrm{b}}$ 18745292065@163.com, ${ }^{\mathrm{c}}$ mengqingxin890831@163.com, ${ }^{\mathrm{d}}$ huqingming1267@126.com
}

\begin{abstract}
Based on higher order contact meshing theory of conjugate curvature, to establish normal tooth profile model of a new tooth profile double helical synchronous belt transmission. Finite element analysis software is used for new composite double helical synchronous belt out the stress analysis of variable tooth profile parameters. According to the theory of rigid flexible coupling contact, use the ANSYS Workbench finite element analysis software carry out static nonlinear analysis to the three dimensional finite element model of single tooth meshing. Study on influence regulation of the stress and deformation of the spiral angle, side gap. Belt pulley structure for the belt tooth and strength layer, provides a digital simulation analysis and design method for tooth shape, structure design of the model. And further through the finite element analysis software analysis of some advantages of the new tooth profile double helical synchronous belt compared with the straight tooth synchronous belt.
\end{abstract}

Keywords-synchronous belt; rigid flexible coupling; profile parameters; FEA; Nonlinear

\section{INTRODUCTION}

All Synchronous belts consist of belt tooth, strong layer back and cloth bag. It is chloroprene rubber, glass fiber rope and nylon three materials are compounded. Synchronous belt is the elastic element that is composed of rubber composite materials. The stress and strain of synchronous belt have constitutive relation of time dependence [1]. Rely on the meshing of belt tooth and belt pulley transfer movement and power, it integrated the advantage of belt drive, chain drive and gear drive [2].

At present, long life, high transmission, positioning accuracy and noise is the bottleneck problem what restricts the development of synchronous belt; it is also currently the important technological subject that the synchronous belt application and development. The double helical synchronous belt has the advantages of high transmission efficiency, low noise, long life compared to the straight tooth synchronous [3].

The bear capability synchronous belt is directly affected the service life and the work efficiency of synchronous belt. In study on the bearing capacity of synchronous belt, Yoshihisa Furukawa [4] et al studied on stress distribution of the belt tooth and the brute force layer through the ABAQUS finite element analysis software. Koyama [5] studied the meshing state of the belt tooth and belt pulley. Then Uchida [6] used the finite element FEM to analysis of load distribution. Milanovic[7] used the
Autodesk Inventor software analysis package and load stress distribution of Simulation of synchronous belt under the variable torque conditions. Na Zheng [8] are analyzed to influence of the different helix angle on stress of the belt tooth and the strength layer by ANSYS finite element analysis software, and Haijun Guo [9] are analyzed to contact stress of the new type high tooth synchronous belt. Zhanguo Li [10] was investigated by MFBD technique on distribution state of belt tooth stress and tensile stress.

\section{THE ESTABLISHMENT OF THE TOOTH PROFILE EQUATION OF DOUBLE HELICAL SYNCHRONOUS BELT}

Because the theory of coordinated conjugate meshing with high-order contact meshing transmission has a high contact strength and bend strength. So use the hot research theory of the theory of coordinated conjugate meshing with high-order contact meshing transmission to establish of normal-plane tooth profile.Fig .1 is normalplane tooth profile of double helical synchronous belt and belt pulley.

As shown in Fig .2 to establish the coordinate system of the normal-plane tooth profile is $\sigma_{n}=\left[O_{n}: x_{n} y_{n} z_{n}\right]$, and the coordinate system of the end-plane tooth profile $\sigma_{p}=\left[O_{n}: x_{p} y_{p} z_{p}\right]$.The normal-plane tooth profile equation is

$$
\left\{\begin{array}{l}
x_{n}=\rho_{i x}+\rho_{i} \sin \theta_{i} \\
y_{n}=\rho_{i y}+\rho_{i} \cos \theta_{i}
\end{array}\right.
$$

In the formula, $\left(\rho_{i x}, \rho_{i y}\right)$ is the coordinate of arc center.$\rho_{i}$ is the radius of circular arc.The space curved surface equation of belt teeth in the coordinate system is

$$
\left\{\begin{array}{l}
x_{p}=\left(\rho_{i x}+\rho_{i} \sin \theta_{i}\right) \\
y_{p}=\left(\rho_{i y}+\rho_{i} \cos \theta_{i}\right) \sin \beta+u \cos \beta \\
z_{p}=-\left(\rho_{i y}+\rho_{i} \cos \theta_{i}\right) \cos \beta+u \sin \beta
\end{array}\right.
$$

Similarly, to establish of the coordinate system of endplane over the belt pulley center $\sigma_{1}=\left[O_{1}: x_{1} y_{1} z_{1}\right]$.The surface equation of belt pulley tooth profile is 
$\left\{\begin{array}{l}x_{1}=\left(r_{i x}+r_{i} \sin \theta_{i}+r_{1}\right) \cos \phi-\left(r_{i y}+r_{i} \cos \theta_{i}\right) \sin \beta \sin \phi \\ y_{1}=\left(r_{i x}+r_{i} \sin \theta_{i}+r_{1}\right) \sin \phi+\left(r_{i y}+r_{i} \cos \theta_{i}\right) \sin \beta \cos \phi \\ z_{1}=p \phi-\left(r_{i y}+r_{i} \cos \theta_{i}\right) \cos \beta\end{array}\right.$

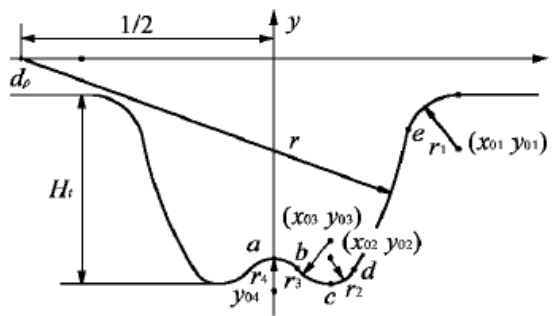

(a)The tooth profile of synchronous belt .

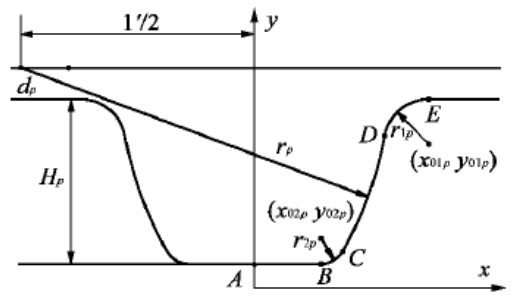

(b)The tooth profile of synchronous belt pulley .

Figure 1. Base tooth of synchronous belt and pulley

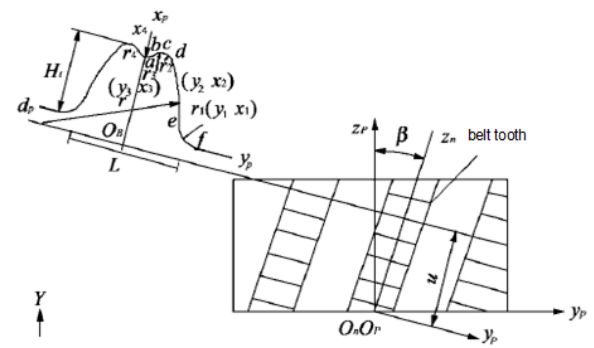

Figure 2. Space model of tooth profile of double helical

\section{THE ESTABLISHMENT OF FINITE ELEMENT MODEL} OF DOUBLE HELICAL SYNCHRONOUS BELT

Through a seamless docking function between UG and ANSYS Workbench, the 3D model of the established completely in UG Import directly into ANSYS Workbench. The basic parameters of this model: the first layer is belt back, its thickness is $2.5 \mathrm{~mm}$, and the material is chloroprene rubber. The second layer is brute force layer, its thickness is $1 \mathrm{~mm}$, and the material is glass fiber. Because there is no glass fiber material in ANSYS Workbench library, so we had to custom glass fiber material.

TABLE I. THE MATERIAL PROPERTIES OF EACH LAYER OF THE SYNCHRONOUS BELT

\begin{tabular}{|c|c|c|c|}
\hline & Units & $\begin{array}{c}\text { Chloroprene } \\
\text { rubber }\end{array}$ & Glass fiber \\
\hline Density $\rho$ & $\mathrm{Kg} / \mathrm{m} 3$ & 1270 & 2600 \\
\hline $\begin{array}{c}\text { elastic modulus } \\
\mathrm{E}\end{array}$ & $\mathrm{N} / \mathrm{m}^{2}$ & 60 & 40000 \\
\hline $\begin{array}{c}\text { Poisson's ratio } \\
\sigma\end{array}$ & & 0.46 & 0.4 \\
\hline
\end{tabular}

\section{EFFECT OF BELT PULLEY TOOTH SLOT TO THE BELT TOOTH STRESS}

The strong layer material is anisotropic; the main bear with circumferential load, the axial intensity is relatively weak. The new tooth profile double helical synchronous belt, belt tooth tip is bearing the circumferential load, also bear part of the axial load, the existence of stress concentration. Reduce the belt tip stress concentration, between left rotation teeth and right rotation teeth open $2 \mathrm{~mm}$ groove on the belt pulley. As shown in Fig .3 is without slot and slotted into two belt pulley structures. As shown in Fig .4, two cases of the belt tooth deformation nephogram of the double helical synchronous belt. Belt pulley without slotted belt tooth local gets large deformation, as shown in Fig .4a). Deformation is relatively uniform after belt pulley slotted; deformation tends to the middle of belt tooth, as shown in Fig .4b).

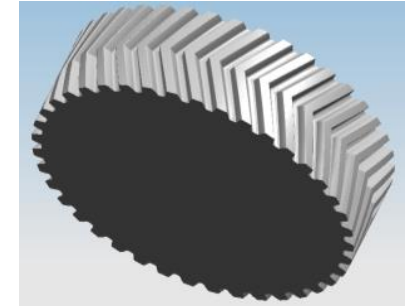

a) Belt pulley (without slotted)

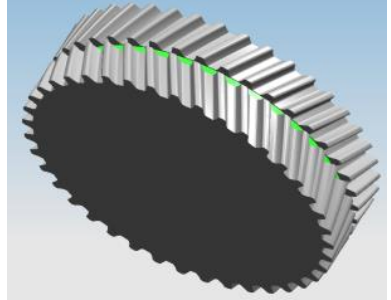

b) Belt pulley (slotted)

Figure 3. Belt pulley structure

The maximum stress location in the belt tooth tip, as shown in Fig .4c), d) are shown. The maximum stress of belt tooth tip is $2.65 \mathrm{MPa}$ before belt pulley slot. The maximum stress of the tooth tip is $0.978 \mathrm{MPa}$ after belt pulley slot. Slotting is not slotted $36.78 \%$. The concentrated stress of the tooth decreased significantly belt after open slot, enhances the strength of belt tooth. And the stress of not slotted belt tooth on the tooth surface is $\sigma_{t \text { max }}=4.96 \mathrm{MPa}$. The belt tooth stress is $\sigma_{t \text { max }}=5.024$ $\mathrm{MPa}$ after the pulley slot. That is because toothed area slightly reduced after slotting. The maximum stress position of the strong layer is on the belt tooth tip , as shown in Fig .4 e), f) .Belt tooth load through the rubber conduction to brute force layer, So the strong layer stress concentration position is the location of stress concentration of belt tooth. The brute force layer maximum stress is $\sigma_{s \max }=18.576 \mathrm{MPa}$ before pulley slot. The brute force layer maximum stress is $\sigma_{s \max }=17.274 \mathrm{MPa}$ after pulley slot. The stress distribution is more evenly distributed after slotting than before.

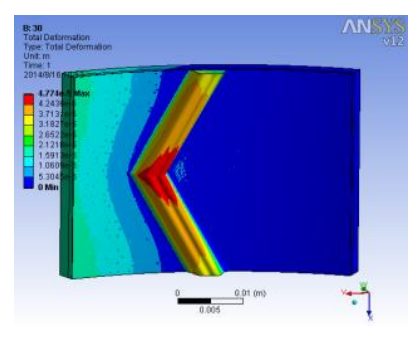

a) The deformation nephogram of the belt tooth (Belt pulley without slotted)

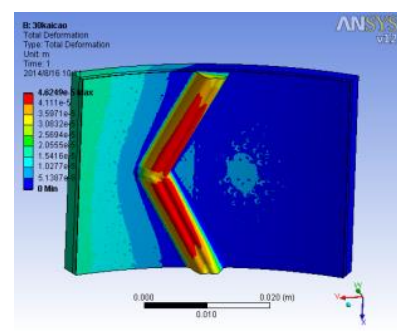

b) The deformation nephogram of the belt tooth (Belt pulley slotted) 


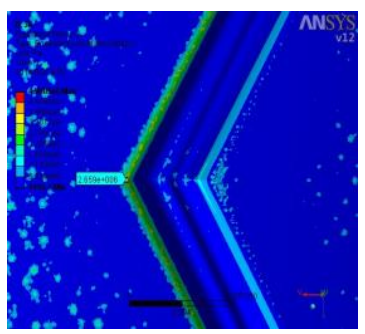

c) The tooth tip stress nephogram (Belt pulley without slotted)

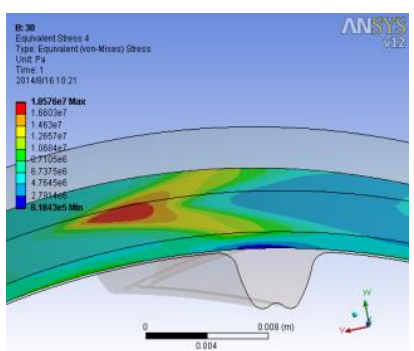

e) The stress nephogram of the brute force layer (Belt pulley without slotted)

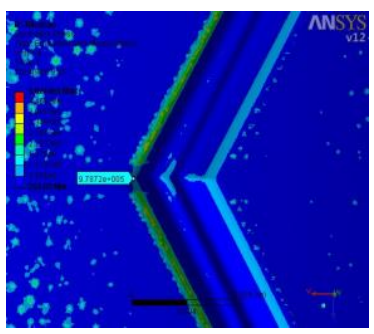

d) The tooth tip stress nephogram (Belt pulley slotted)

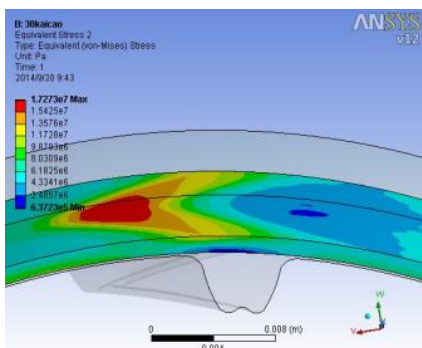

f) The stress nephogram of the brute force layer(Belt pulley slotted)
Figure 4. The stress and deformation nephogram of the double helical synchronous belt

\section{THE EFFECT OF THE DIFFERENCE OF SIDE GAP TO SYNCHRONOUS BELT}

In a complete engagement state model, Side gap respectively is $0.1 \mathrm{~mm}, 0.2 \mathrm{~mm}, \mathrm{~mm} 0.3$. Fig .5a), b), c) represents a different side gap displacement distribution nephogram, When the side gap smaller, belt tooth top and the tooth groove contact deformation greater. The maximum stress belt tooth is smaller. Stress values were $\sigma_{t \max }=4.65 \mathrm{MPa}, 4.96 \mathrm{MPa}, 5.16 \mathrm{MPa}$, as shown in Fig .5d), e), f). Small backlash (0.1 mm), belt the tooth top right arc curve contact with the tooth groove on the right side of the root arc curve, To the belt teeth a clockwise resistance torque, reduce the maximum stress of belt tooth root. As shown in Fig .5a), d). So the side gap decreases make the top curve of belt tooth and tooth groove bottom curve contact, to the belt tooth generated resistance torque effect.

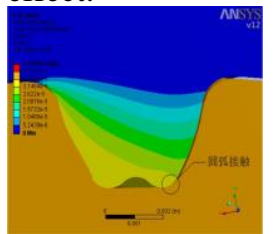

a) displacement nephogram $(0.1 \mathrm{~mm})$

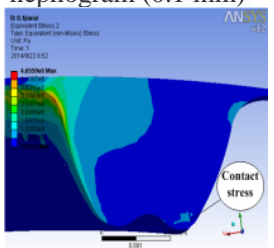

d) stress nephogram $(0.1 \mathrm{~mm})$

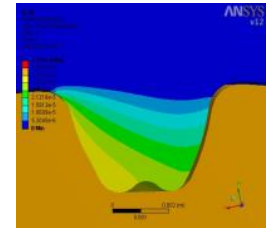

b) displacement nephogram $(0.2 \mathrm{~mm})$

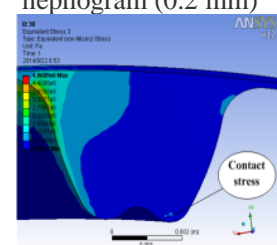

e) stress nephogram $(0.2 \mathrm{~mm})$

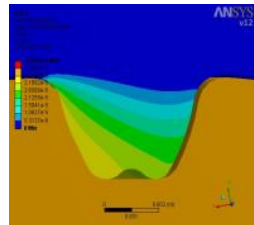

c) displacement nephogram $(0.3 \mathrm{~mm})$

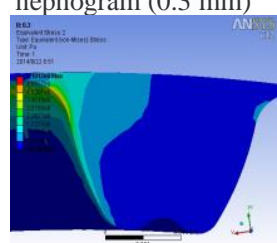

c) stress nephogram $(0.3 \mathrm{~mm})$
Figure 5. The Fig . 3 different side gap belt tooth stress and displacement distribution nephogram

\section{THE INFLUENCE OF HELIX ANGLE TO DOUBLE HELICAL SYNCHRONOUS BELT OF A NEW BELT TOOTH PROFILE STRESS DISTRIBUTION}

The helix angle is $\beta=25^{\circ}, 30^{\circ}, 35^{\circ}, 40^{\circ}$, the new tooth profile double helical synchronous belt, belt pulley set up perfect meshing state model. In the computation model extracted the maximum equivalent stress $\sigma_{t \max }$ of belt tooth and the maximum equivalent stress of brute force layer $\sigma_{s \max }$,The establishment of spiral angle of $\beta$ and $\sigma_{t \max }$ and $\sigma_{s \max }$ function relation.As shown in Fig .6. Brute force layer $\sigma_{s \max }$ with $\beta$ increases.Belt tooth stress changes relatively complex.when $\beta=30^{\circ}$, is a minimum. Considering the double helical synchronous belt and belt pulley angle of helix primaries $\beta=30^{\circ}$.

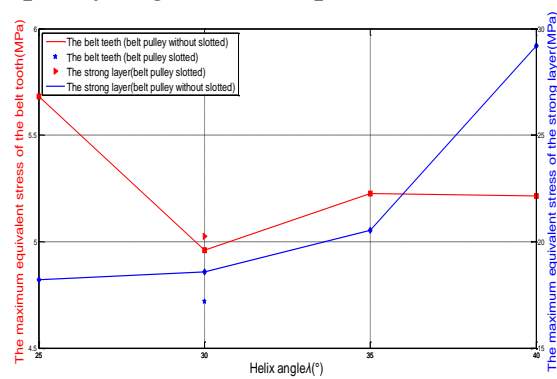

Figure 6. The relationship between the maximum equivalent stress and the spiral angle

\section{STRAIGHT TOOTH SYNCHRONOUS BELT} CONTRASTIVE STRESS IN SYNC WITH NEW TOOTH PROFILE OF HERRINGBONE GEAR

Straight tooth synchronous belt have the same tooth shape with the new tooth profile herringbone gear end face, Synchronous belt is controlled by study on equivalent stress load under the same conditions, the spiral angle of belt tooth is $30^{\circ}$.The maximum stress of tooth is $\sigma_{t \max }=5.024 \mathrm{MPa}$, Brute force layer maximum stress is $\sigma_{s \max }=17.274 \mathrm{MPa}$, The stress nephogram of belt teeth and brute force layer of straight tooth synchronous is shown in Fig .7,a).Toothed equivalent stress distribution nephogram, The maximum stress at the tooth root. The maximum stress of the toothed belt is $\sigma_{t \max }=9.05 \mathrm{MPa}$ Brute force layer stress nephogram as shown in Fig .7b), $\sigma_{s \max }=120 \mathrm{MPa}$. The equivalent stress contours of belt shown in Fig .7c)The new tooth profile herringbone tooth synchronous belt the maximum stress is less than the straight tooth synchronous tooth belt.

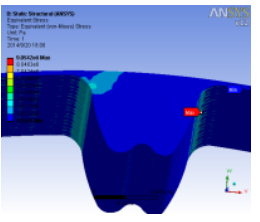

a) belt tooth stress distribution

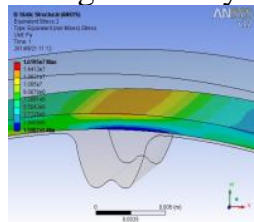

b) brute force layer equivalent stress distribution

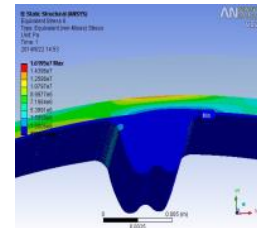

c) belt equivalent stres
Figure 7. The stress nephogram of straight tooth synchronous teeth and brute force layer 


\section{CONCLUSION}

1. Through establishing the finite element model before pulley slot and after pulley slot carries on the contrast analysis under the same load and the same boundary conditions. Obtained the belt tooth wear more evenly after the pulley slot than before the belt pulley slot, After the pulley slot effectively avoid toothed local serious abrasion phenomenon.

2 Through contrast and analysis of herringbone belt finite element model of different side clearance. To be able to get along with the increase of the side gap of the tooth root stress decreases the conclusion. To improve the tooth profile parameters and decreasing the tooth root stress plays an important role.

3. Compared double helical synchronous belt of spiral angle respectively $25^{\circ} 、 30^{\circ} 、 35^{\circ} 、 40^{\circ}$ the maximum equivalent stress of strength layer under the same load. We obtained that with the increasing of helix angle, strength layer with large maximum equivalent stress reduction. And through the straight tooth synchronous belt and the new tooth profile double helical synchronous belt stress analysis. We can find a new tooth profile double helical synchronous belt tooth stress is smaller than the straight tooth synchronous belt.

4. We analyzed to wear and stress of straight tooth synchronous belt and herringbone gear synchronous belt by ANSYS Workbench Analysis software. The double helical synchronous belt has the advantages of less stress, less wear, longer life compared to the straight tooth synchronous belt.

\section{ACKNOWLEDGMENT}

This project is supported by National Science Foundation of China (51175273); Science and technology project of Qiqihar (GYGG-201313); the innovation of scientific research of Qiqihar University graduate (YJSCX2014-024X).

\section{REFERENCES}

[1] The Japanese belt transmission technical committee, "Belt drives design and precise delivery utility," Bin Qi, translation. Beijing: Chemical Industry Press,2013,pp.237-278

[2] Jianhua Guo, Hongyuan Jiang, Qingming $\mathrm{Hu}$, "Double Helical Synchronous Belt Transmission Design based on Theory of High Degree Contact Mesh," Mechanical transmission, vol.37, 2013, pp.17-21,doi:1004-2539(2013) 08-0017-04.

[3] Jianhua Guo, Hongyuan Jiang, Yizhen Wu, "Double Helical Synchronous Belt Transmission Design," Materials Science Forum,vol.800-801,2014,pp.672-677.

[4] Yoshihisa Furukawa, Kiyohisa Tomono, Hideaki Takahashi, and Takanao Uchida, "Analysis of Stress Distribution of Timing Belts by FEM," Copyright 1997 Society of Automotive Engineers, Inc.1997, pp.139-144

[5] Koyama, T, Murakani K, Nakai H, et al, "On Load Distribution of Toothed Belts with the Same Pitch (1st report)," Trans. JSME, vol.337, 1978, pp.312-320.

[6] Uchida T, Furukawa Y, Tomono K, et al, "Pitch difference and belt tooth configuration effect on load distribution of timing belt using fem analysis," Development, 2009,pp.03-25.

[7] MilanovicI I., Stojanovic B. Blagojevic M., et al, "Influence of torque variation on timing belt drive's load distribution," Serbia, IRMES 2011, pp.559-562.

[8] Na Zheng, "Design and simulation analysis of double helical synchronous belt transmission," Harbin Institute of Technology, Jun.2011.

[9] Haijun Guo, "The Contacting Stress Analysis of New Type High - tooth Synchronous Belt Based on ANSYS," Northwestern Poly technical University,Mar.2006.

[10] Zhangguo LI, Xiaochen Shi, Qin Shuan, et al., "Study on Mesh Dynamics Spur Tooth Synchronous Belt based on MFDB,"2012, pp.25-27, doi: 1004- 2539( 2012) 09- 0025- 03. 